\title{
Outcome of intra-articular lumbar facet joint corticosteroid injection according to the severity of facet joint arthritis
}

\author{
DONG GYU KWAK ${ }^{1}$, SANG GYU KWAK ${ }^{2}$, AH YOUNG LEE ${ }^{3}$ and MIN CHEOL CHANG ${ }^{1}$ \\ ${ }^{1}$ Department of Physical Medicine and Rehabilitation, College of Medicine, Yeungnam University, Daegu 42415; \\ ${ }^{2}$ Department of Medical Statistics, College of Medicine, Catholic University of Daegu, Daegu 42472; \\ ${ }^{3}$ Department of Physical Therapy, College of Rehabilitation Sciences, Daegu University, Daegu 38453, Republic of Korea
}

Received January 20, 2019; Accepted August 21, 2019

DOI: $10.3892 /$ etm.2019.8031

\begin{abstract}
Lumbar facet joint osteoarthritis (FJOA) caused by degenerative change(s) is considered to be the main cause of facet joint-origin low back pain (LBP). Intra-articular lumbar facet joint (IA LFJ) corticosteroid injection is widely used for controlling pain induced by FJOA. In the current study, the outcomes of IA LFJ corticosteroid injection were evaluated according to the severity of FJOA. A total of 50 patients who received IA LFJ corticosteroid injections for the treatment of LFJ pain were recruited. Patients were classified into three groups according to the severity of FJOA, which was indicated during a lumbar axial MRI. A total of 10 patients were assigned to group A (patients with mild FJOA), 27 to group B (patients with moderate FJOA) and 13 to group $\mathrm{C}$ (patients with severe FJOA). Pain intensity was evaluated using a numerical rating scale (NRS) prior to treatment and at 1, 2 and 3 months after treatment. A total of $26(52 \%)$ patients experienced successful treatment outcomes (defined as $>50 \%$ reduction in NRS score at 3 months). Patients in all groups demonstrated a significant decrease in NRS scores at 1,2 and 3 months after IA LFJ corticosteroid injection compared with the pre-treatment score $(\mathrm{P}<0.001)$. However, the effect of IA LFJ corticosteroid injection was not significantly different among the three groups $(\mathrm{P}=0.889)$. The results demonstrated that facet joint-origin LBP was significantly reduced after IA LFJ corticosteroid injection, regardless of the severity of FJOA. The results of the current study indicated that IA LFJ corticosteroid injection is a beneficial clinical option for managing LBP caused by FJOA.
\end{abstract}

Correspondence to: Professor Min Cheol Chang, Department of Physical Medicine and Rehabilitation, College of Medicine, Yeungnam University, 317-1 Daemyungdong, Daegu 42415, Republic of Korea E-mail:wheel633@gmail.com

Abbreviations: LBP, low back pain; LFJ, lumbar facet joint; IA, intra-articular; FJOA, facet joint osteoarthritis; NRS, numerical rating scale; VAS, visual analogue scale

Key words: lumbar facet joint, osteoarthritis, corticosteroid injection, lower back pain, severity

\section{Introduction}

Lower back pain (LBP) is the most common pain syndrome that can cause disability $(1,2)$. Pathologies of the lumbar intervertebral discs, lumbar facet joints (LFJs) and the sacroiliac joint are potential sources of chronic LBP $(3,4)$. Disorders of the facet joints represent a common source of LBP. In previous studies, the prevalence of chronic LBP caused by pathologies of the facet joints was reported to be $\sim 30 \%$, which increased with age as LBP exhibits similar characteristics with arthritis (5-8). Osteoarthritis of the LFJs due to degenerative change(s) is considered to be the main cause of facet joint-origin LBP (9). Degenerative changes in LFJs can lead to abnormal stress and strain, resulting in increased load on the facet joint (10). Additionally, increased mechanical load and subsequent inflammation activate nociceptors within and surrounding the joints, which further exacerbate facet joint-origin LBP (10-12).

To manage facet joint-origin pain in clinical practice, intra-articular (IA) LFJ corticosteroid injections are widely and conventionally used, and the positive effect of this treatment has been reported in a number of previous studies (13-20). The effect of IA LFJ corticosteroid injection may be different according to the degree of LFJ degeneration. The prediction of treatment outcome after IA LFJ corticosteroid injection may therefore enable clinicians to apply a more appropriate therapeutic method to patients with LBP. However, little is known about the treatment outcomes of IA LFJ corticosteroid injections according to the severity of facet joint osteoarthritis (FJOA). Therefore, the present study aimed to evaluate whether the severity of FJOA affects IA LFJ corticosteroid injection treatment.

\section{Patients and methods}

Patients. The current retrospective study recruited 50 patients who visited the spinal center of Yeungnam University Hospital between March 2014 and Aug 2018 for the management of LFJ pain and received IA LFJ corticosteroid injection treatment (Table I). Patients were included based on the following criteria: (i) $\geq 6$-month history of axial LBP without radicular symptoms (duration of pain was examined by asking patients directly), (ii) aged between 20 and 79 years, (iii) local paraspinalis tenderness with increased pain upon hyperextension, rotation or 
lateral bending of the lower lumbar spine (iv) $\geq 80 \%$ temporary pain relief following a diagnostic block with IA injection of $0.5 \mathrm{ml}$ of $1 \%$ lidocaine (temporary pain relief, assessed using a numerical rating scale (NRS) (21), was evaluated using a survey that the patients filled out) and (v) failure to respond to medication (meloxicam $15 \mathrm{mg}$ and/or acetaminophen/tramadol hydrochloride $325 / 37.5 \mathrm{mg}$ ) or physical therapy prior to IA LFJ corticosteroid injection (LBP $\geq 4$ on a NRS). Each patient underwent a lumbar spine MRI. Patients with disc herniation, lumbar spinal stenosis, spinal instability, coagulopathy, allergy to iodinated contrast, rheumatic disorders or any uncontrolled medical or psychiatric conditions were excluded from the current study. The present study was approved by the Ethics Committee of Yeungnam University Hospital.

The 50 patients recruited into the current study were classified into three subgroups according to the results of routinely performed lumbar axial MRI, and based on the study by Maataoui et al (22) (Fig. 1): Group A, the lumbar MRI revealed narrowing of the LFJ space and the presence of small osteophytes (mean age, $66.0 \pm 11.0$ years; 5 males, 5 females); Group B, the MRI revealed narrowing of the joint space, moderate osteophytes and/or subchondral erosions

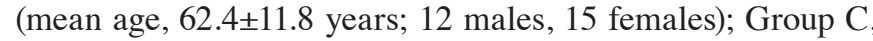
the MRI revealed narrowing of the joint space and the presence of large osteophytes and subchondral erosion/cysts (mean age, $68.5 \pm 7.7$ years; 6 males, 7 females).

Procedures. Treatment was administered using a posterior approach, where patients were placed the prone position for C-arm fluoroscopy (Siemens Healthineers; Table II) and a cushion was placed below the lower abdomen to straighten the lumbar spine. The $\mathrm{C}$-arm tube was angled cephalad and rotated until it was at a tangent to the LFJ space. Under C-arm fluoroscopy, after confirming IA access by injecting $0.3 \mathrm{ml}$ of contrast into the LFJ space, $10 \mathrm{mg}(0.25 \mathrm{ml})$ of dexamethasone mixed with $0.25 \mathrm{ml}$ of $0.125 \%$ bupivacaine was injected using a 26-gauge and a $90 \mathrm{~mm}$ spinal needle (Fig. 2). The IA LFJ corticosteroid injection was administered once for each patient. During the follow-up period, which occurred for a duration of 3 months, all the recruited patients received no additional oral medication or physical therapy.

Outcome measures. Pain intensity was assessed using an NRS, which was administered prior to treatment and at 1 , 2 and 3 months after IA LFJ corticosteroid injection. NRS score was measured once for each follow-up. Successful treatment was defined as a $>50 \%$ reduction in NRS score at 3 months compared with the pre-treatment NRS score. To validate changes in pain reduction, NRS scores were evaluated by assessing the difference between the pretreatment and the 3 month follow-up treatment NRS scores [change in NRS $(\%)=($ pretreatment score-score at 3 months after treatment)/pretreatment score $\mathrm{x} 100]$.

Statistical analysis. The demographic characteristics and baseline clinical variables were summarized using descriptive analysis. Values of quantitative variables are presented as the mean \pm standard deviation, while qualitative variables are presented as frequencies and percentages. Demographic data and successful pain relief were compared among the three groups using the chi-squared test for qualitative variables and one-way ANOVA for quantitative variables. A multiple comparisons test was performed using the Scheffe method. Analysis of transition aspect for NRS scores in all recruited patients, by time, was performed using a repeated measures ANOVA. The analysis of transition aspect for NRS scores by time, group and interaction effects (time differences by group) was performed using a repeated measure two (time and factor) factor analysis. Multiple comparisons were performed by contrast with Bonferroni's correction. $\mathrm{P}<0.05$ was considered to indicate a statistically significant difference. All tests were two-sided and data were analyzed using SPSS version 22.0 (IBM Corp.).

\section{Results}

NRS scores were significantly decreased at the follow-up evaluations of each patient. All patients completed the study and no adverse effects were observed from treatment. No statistically significant differences were observed in demographic data among groups (Table I). Among all patients, mean NRS scores were significantly reduced as follows: Pretreatment NRS, 4.4 \pm 1.1 ; NRS at 1 month, 2.3 \pm 1.3 ; NRS at 2 months, $2.4 \pm 1.4$ and NRS at 3 months, $2.5 \pm 1.4$ (Fig. 3A). NRS scores changed significantly over time $(\mathrm{P}<0.001)$. Compared with pretreatment, the NRS scores at each evaluation time point were significantly lower $(\mathrm{P}<0.001)$. A total of $26(52 \%)$ patients experienced successful pain relief $(\geq 50 \%)$ after IA LFJ corticosteroid injection (Table I).

All groups exhibited a significant decrease in NRS score at each follow-up evaluation. In group A, the mean NRS score significantly decreased after treatment. The pretreatment NRS score was $4.3 \pm 0.8$. At 1 month, the mean NRS was $2.2 \pm 0.9$, at 2 months, $2.2 \pm 1.2$ and at 3 months, 2.1 \pm 1.3 (Fig. 3B). In group $B$, the mean NRS decreased from $4.4 \pm 1.1$ before treatment to $2.4 \pm 1.6$ at 1 month, to $2.5 \pm 1.6$ at 2 months, and to $2.6 \pm 1.6$ at 3 months after treatment. In group $\mathrm{C}$, the mean NRS was $4.5 \pm 1.2$ before treatment, $2.3 \pm 1.1$ at 1 month, $2.4 \pm 1.3$ at 2 months, and $2.8 \pm 1.1$ at 3 months after treatment. Among the three groups, the NRS scores at 1,2 and 3 months were significantly lower than the pretreatment scores $(\mathrm{P}<0.001)$. NRS scores from pretreatment to each evaluation time point were significantly lower in all three groups $(\mathrm{P}<0.001)$. However, changes in NRS scores were not significantly different between groups $(\mathrm{P}=0.889)$. A period of 3 months after treatment, $6(60.0 \%)$ patients in group A, $14(51.9 \%)$ in group B and 6 $(46.2 \%)$ in group $C$ reported successful pain relief $(\geq 50 \%)$. The rates of successful pain relief at 3 months after treatment were not significantly different among the three groups $(\mathrm{P}=0.805$; Table I).

\section{Discussion}

In the present study, the clinical effects of IA LFJ corticosteroid injection were evaluated and the effects of injection were compared according to the severity of FJOA. The results demonstrated that pain severity, which was measured via the NRS scoring system, was significantly decreased following IA LFJ corticosteroid injection in all three groups, which were classified according to the severity of FJOA. Furthermore, the 
Table I. Demographic characteristics and baseline clinical data of the patients included in the current study. Data regarding age and pain duration are presented as mean \pm standard deviation.

\begin{tabular}{lccccr}
\hline & \multicolumn{4}{c}{ Group } & \\
\cline { 2 - 5 } Variable & $\mathrm{A}(\mathrm{n}=10)$ & $\mathrm{B}(\mathrm{n}=27)$ & $\mathrm{C}(\mathrm{n}=13)$ & Total $(\mathrm{n}=50)$ & P-value \\
\hline Age (years) & $66.0 \pm 11.0$ & $62.4 \pm 11.8$ & $68.5 \pm 7.8$ & $64.7 \pm 10.9$ & 0.229 \\
NRS (pre-treatment) & $4.3 \pm 0.8$ & $4.4 \pm 1.1$ & $4.5 \pm 1.2$ & $4.4 \pm 1.1$ & 0.874 \\
Pain duration (months) & $15.8 \pm 10.2$ & $20.6 \pm 20.5$ & $18.1 \pm 14.4$ & $19.0 \pm 17.2$ & 0.740 \\
Sex, $\mathrm{n}(\%)$ & & & & \\
$\quad$ Male & $5(50.0)$ & $12(44.4)$ & $6(46.2)$ & $23(46.0)$ & 0.956 \\
$\quad$ Female & $5(50.0)$ & $15(55.6)$ & $7(53.9)$ & $27(54.0)$ & \\
Successful pain relief, $\mathrm{n}(\%)$ & & & & & \\
$\quad$ Failure & $4(40.0)$ & $13(48.2)$ & $7(53.9)$ & $24(48.0)$ & 0.805 \\
Success & $6(60.0)$ & $14(51.9)$ & $6(46.2)$ & $26(52.0)$ & \\
\hline
\end{tabular}

NRS, numerical rating scale.

Table II. Treated facet joint level of each group.

\begin{tabular}{lcrr}
\hline Lumbar level, n (\%) & Group A & Group B & Group C \\
\hline L3/4 & $2(20.0)$ & $3(11.1)$ & $2(15.4)$ \\
L4/5 & $5(50.0)$ & $16(59.3)$ & $6(46.2)$ \\
L5/S1 & $3(30.0)$ & $8(29.6)$ & $5(38.4)$ \\
\hline
\end{tabular}

L, lumbar spine; S, sacral spine
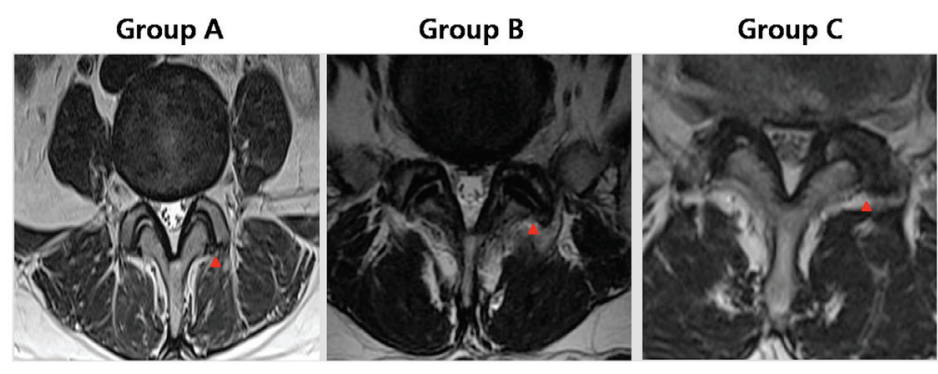

Figure 1. Grading of facet joint osteoarthritis in representative T2-weighted axial MRI images of the lumbar spine. Group A, narrowing of the lumbar facet joint space and presence of a small osteophyte; group B, narrowing of the joint space, moderate osteophytes and/or subchondral erosions; and group C, narrowing of the joint space, large osteophytes and subchondral erosion/cysts are apparent. Red arrows indicate the facet joints.

pain-reducing effect of IA LFJ corticosteroid injection was not significantly different among the three groups.

FJOA-associated LBP may originate from inflammation within the area surrounding the LFJ $(23,24)$. The anti-inflammatory properties of injected corticosteroids block the production and release of inflammatory mediators, consequently inhibiting processes associated with inflammation (25). Furthermore, corticosteroids inhibit neural transmission within nociceptive C-fibers (26). The significant pain reduction observed in the current study appears to have been induced by the effects of the corticosteroid. Additionally, injection of bupivacaine in patients may block pain transmission in the synovial lining within nociceptive C-fibers and reduce ectopic discharge (27). Therefore, bupivacaine, at least in part, may have contributed

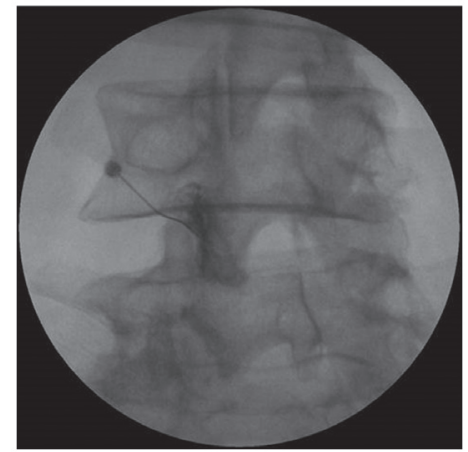

Figure 2. Intra-articular lumbar facet joint corticosteroid injection. C-arm fluoroscopy-guided intra-articular contrast injection into the left L4-5 facet joint. 

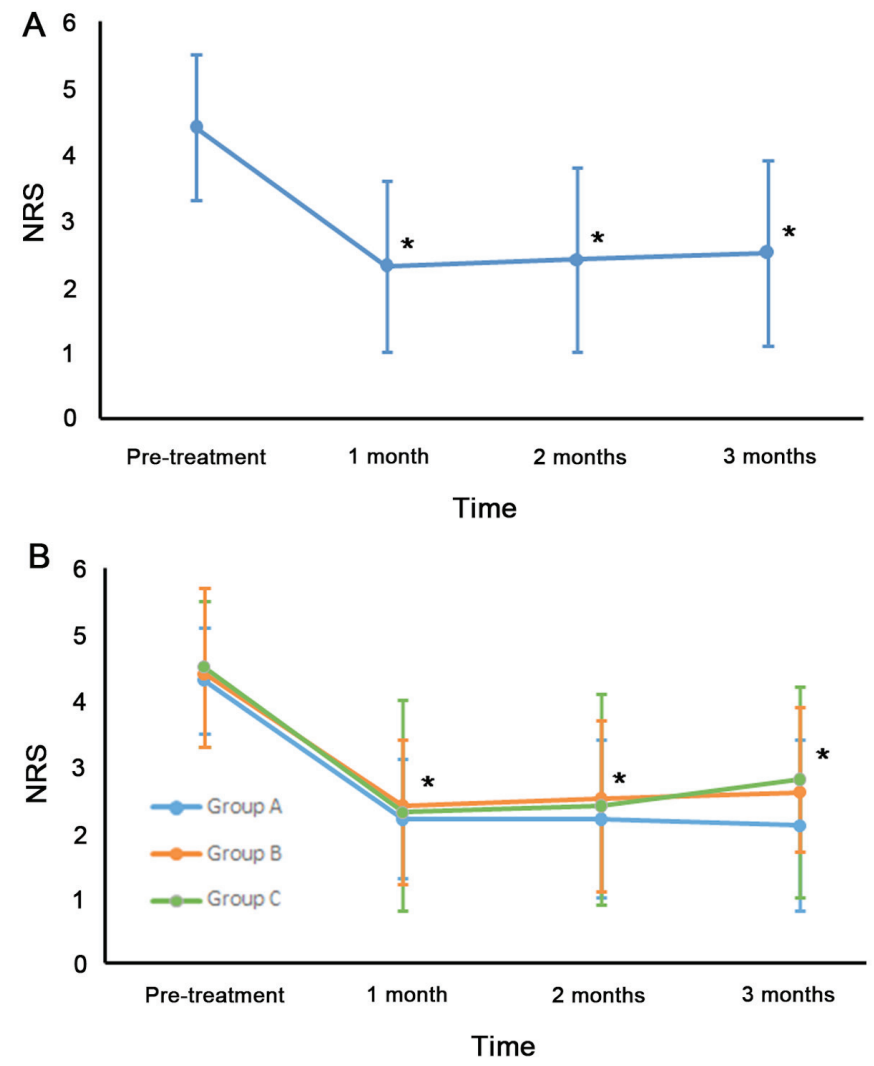

Figure 3. NRS score for lumbar facet joint-origin pain over the assessment period. (A) Mean NRS scores of all recruited patients. The mean NRS scores at 1,2 and 3 months after intra-articular lumbar facet joint corticosteroid injection. (B) Changes in the mean NRS in each group at 1,2 and 3 months after intra-articular lumbar facet joint corticosteroid injection. NRS, numerical rating scale. ${ }^{*} \mathrm{P}<0.001$ vs. pre treatment.

to the extensive pain relief reported in the current study. The results of the current study were contrary to the expectation that the effect of IA LFJ injection would be diminished in patients with severe FJOA. Although some patients exhibited severe FJOA, there was no statistically significant difference in the effect of injection between patients with severe FJOA and patients with non-severe FJOA. The corticosteroid can be suggested to exhibit anti-inflammatory and analgesic effects that are sufficient to alleviate all LFJ-origin LBP, regardless of the severity of FJOA (28). Bupivacaine has also been known to block transmissions in nociceptive C-fibers (27). Additionally, structures, including lumbar paraspinalis muscles, paraspinal ligament and intervertebral discs, may prevent or mitigate the severe mechanical loading on the LFJ.

In the current study, the degree of pre-treatment facet joint-origin pain was not significantly different among the three groups. However, the present study included a relatively small number of patients. Additionally, to the best of our knowledge, no previous study has reported the association between the level of pain and structural changes of the facet joint. Suri et al (29) indicated that severe FJOA is more often observed in patients exhibiting back pain than in those without back pain. However, the aforementioned study did not evaluate the degree of pain according to severity of FJOA. Therefore, for this to be confirmed, further studies are required.

To the best of our knowledge, a total of four previous studies have reported the effects of IA LFJ corticosteroid injection in controlling LFJ-origin pain (30-33). In 2011, Kawu et al (30) performed IA LFJ corticosteroid injection treatment in 10 patients, $90 \%$ of whom experienced a pain reduction of $>50 \%$ according to visual analogue scale (VAS) scores 6 months after treatment. In the same year, Celik et al (31) performed IA LFJ corticosteroid injection treatment in 40 patients, with the mean VAS scores being reduced by $\sim 75 \%$ of pre-treatment scores 6 months after treatment. In 2013, Ribeiro et al (32) performed IA LFJ corticosteroid injection treatment in 31 patients, who exhibited a $\sim 50 \%$ reduction in mean VAS of pre-treatment scores 3 months after treatment. In 2017, Do et al (33) performed IA LFJ corticosteroid injection treatment in 30 patients and reported that the mean NRS score was reduced from 5 at pretreatment to 3.2 at 6 months following injection. In the current study, patients were classified into 3 groups according to lumbar axial MRI results. Consistent with the results of previous studies, a significant decrease was observed in mean NRS scores, in all groups, after IA LFJ corticosteroid injection (13-20). Additionally, the current study is, to the best of our knowledge, the first to evaluate and compare treatment outcomes of IA LFJ corticosteroid injection according to the severity of FJOA.

In conclusion, the results of the current study demonstrated that the IA LFJ corticosteroid injection treatment was effective, regardless of FJOA severity. I IA LFJ corticosteroid injections may be a useful clinical option for the management of FJOA-mediated LBP. However, the present study had certain limitations, including its retrospective design and relatively small sample size. Additionally, the long-term effect of IA LFJ corticosteroid injection were not evaluated. Therefore, further studies are required to overcome these limitations and support the results of the present study.

\section{Acknowledgements}

Not applicable.

\section{Funding}

The present study was supported by a National Research Foundation of Korea grant funded by the Korean government (grant no. NRF-2019R1F1A1061348).

\section{Availability of data and materials}

The datasets used and/or analyzed during the current study are available from the corresponding author on reasonable request.

\section{Authors' contributions}

DGK and MCC performed wrote the manuscript and acquired the data. SGK and AYL designed the current study, analyzed the data and revised manuscript. MCC supervised the study and conducted critical revision of manuscript. All authors read and approved the final manuscript.

\section{Ethics approval and consent to participate}

The present study was approved by the Ethics Committee of Yeungnam University Hospital, and written informed consent was obtained from all patients. 


\section{Patient consent for publication}

All participants provided written informed consent for publication.

\section{Competing interests}

The authors declare that they have no competing interests.

\section{References}

1. Vekaria R, Bhatt R, Ellard DR, Henschke N, Underwood M and Sandhu H: Intra-articular facet joint injections for low back pain: A systemic review. Eur Spine J 25: 1266-1281, 2016.

2. Perolat R, Kastler A, Nicot B, Pellat JM, Tahon F, Attye A, Heck O, Boubagra K, Grand S and Krainik A: Facet joint syndrome: From diagnosis to interventional management. Insights Imaging 9: 773-789, 2018.

3. Schwarzer AC, Aprill CN, Derby R, Fortin J, Kine G and Bogduk N: Clinical features of patients with pain stemming from the lumbar zygapophysial joints. Is the lumbar facet syndrome a clinical entity? Spine (Phila Pa 1976) 19: 1132-1137, 1994.

4. Bogduk N: The anatomical basis for spinal pain syndromes. J Manipulative Physiol Ther 18: 603-605, 1995.

5. Ashton IK, Ashton BA, Gibson SJ, Polak JM, Jaffray DC and Eisenstein SM: Morphological basis for back pain: The demonstration of nerve fibers and neuropeptides in the lumbar facet joint capsule but not in ligamentum flavum. J Orthop Res 10 72-78, 1992.

6. Kuslich SD, Ulstrom CL and Michael CJ: The tissue origin of low back pain and sciatica: A report of pain response to tissue stimulation during operations on the lumbar spine using local anesthesia. Orthop Clin North Am 22: 181-187, 1991.

7. Manchikanti L, Boswell MV, Singh V,Pampati V, Damron KS and Beyer CD: Prevalence of facet joint from in chronic spinal pain of cervical, thoracic, and lumbar regions. BMC Musculoskelet Disord 5: 15, 2004.

8. Marks R: Distribution of pain provoked from lumbar facet joints and related structures during diagnostic spinal infiltration. Pain 39: 37-40, 1989.

9. Eubanks JD, Lee MJ, Cassinelli E and Ahn NU: Prevalence of lumbar facet arthrosis and its relationship to age, sex, and race: An anatomic study of cadaveric specimens. Spine (Phila Pa 1976) 32: 2058-2062, 2007.

10. Gellhorn AC, Katz JN and Suri P: Osteoarthritis of the spine: The facet joints. Nat Rev Rheumatol 9: 216-224, 2013.

11. Lawrence RC: Estimates of the prevalence of arthritis and selected musculoskeletal disordersin the United States. Arthritis Rheum 16: 427-441, 1989.

12. Kang YM, Choi WS and Pickar JG: Electrophysiologic evidence for an intersegmental reflex pathway between lumbar paraspinal tissues. Spine (Phila Pa 1976) 27: E56-E63, 2002.

13. Cavanaugh JM, Ozaktay AC, Yamashita T, Avramov A, Getchell TV and King AI: Mechanisms of low back pain: A neurophysiologic and neuroanatomic study. Clin Orthop Relat Res: 166-180, 1997.

14. Cohen SP, Huang JH and Brummett C: Facet joint pain-advances in patient selection and treatment. Nat Rev Rheumatol 9: 101-116, 2013.

15. Bellamy N, Campbell J, Robinson V, Gee T, Bourne R and Wells G: Intraarticular corticosteroid for treatment of osteoarthritis of the knee. Cochrane Database Syst Rev 19: CD005328, 2006.
16. Buchbinder R, Green S and Youd JM: Corticosteroid injections for shoulder pain. Cochrane Database Syst Rev: CD004016, 2003.

17. Machado E, Bonotto D and Cunali PA: Intra-articular injections with corticosteroids and sodium hyaluronate for treating temporomandibular joint disorders: A systemic review. Dental Press J Orthod 18: 128-133, 2013.

18. Carette S, Marcoux S, Truchon R, Grondin C, Gagnon J, Allard Y and Latulippe M: A controlled trial of corticosteroid injections into facet joints for chronic low back pain. N Engl J Med 325: 1002-1007, 1991.

19. Schulte TL, Pietilä TA, Heidenreich J, Brock M and Stendel R: Injection therapy of lumbar facet syndrome: A prospective study. Acta Neurochir (Wien) 148: 1165-1172, 2006.

20. Manchikanti L, Manchikanti KN, Manchukonda R, Cash KA, Damron KS, Pampati V and McManus CD: Evaluation of lumbar facet joint nerve blocks in the management of chronic low back pain: A preliminary report of a randomized, double-blind controlled trial: Clinical trial NCT00355914. Pain Physician 10: 425-440, 2007.

21. Farrar JT, Young JP Jr, LaMoreaux L, Werth JL and Poole RM: Clinical importance of changes in chronic pain intensity measured on an 11-point numerical pain rating scale. Pain 94: 149-158, 2001.

22. Maataoui A, Voql TJ, Middendorp M, Kafchitsas K and Khan MF: Association between facet joint osteoarthritis and the Oswestry Disability Index. World J Radiol 6: 881-885, 2014.

23. Groen GJ, Baljet B and Drukker J: Nerves and nerve plexuses of the human vertebral column. Am J Anat 188: 282-296, 1990.

24. Chen C, Lu Y, Kallakuri S, Patwardhan A and Cavanaugh JM: Distribution of A-delta and C-fiber receptors in the cervical facet joint capsule and their response to stretch. J Bone Joint Surg Am 88: 1807-1816, 2006.

25. Lee DG, Ahn SH and Lee J: Comparative effectiveness of pulsed radiofrequency and transforaminal steroid injection for radicular pain due to disc herniation: A prospective randomized trial. J Korean Med Sci 31: 1324-1330, 2016.

26. Olmarker K, Byröd G, Cornefjord M, Nordborg C and Rydevik B: Effects of methylprednisolone on nucleus pulposus-induced nerve root injury. Spine (Phila Pa 1976) 19: 1803-1808, 1994.

27. Lee DG, Cho YW, Cho KH and Chang MC: Management of refractory sciatic neuropathic pain using ultrasound-guided pulsed radiofrequency. J Back Musculoskelet Rehabil 30: 1141-1145, 2017.

28. Barnes PJ: Anti-inflammatory actions of glucocorticoids: Molecular mechanisms. Clin Sci (Lond) 94: 557-572, 1998.

29. Suri P, Hunter DJ, Rainville J, Guermazi A and Katz JN: Presence and extent of severe facet joint osteoarthritis are associated with back pain in older adults. Osteoarthritis Cartilage 21: 1199-1206, 2013.

30. Kawu AA, Olawepo A and Salami AO: Facet joints infiltration: A viable alternative treatment to physiotherapy in patients with low back pain due to facet joint arthropathy. Niger J Clin Pract 14: 219-222, 2011.

31. Celik B, Er U, Simsek S, Altug T and Bavbek M: Effectiveness of lumbar zygapophysial joint blockage for low back pain. Turk Neurosurg 21: 467-470, 2011.

32. Ribeiro LH, Furtado RN, Konai MS, Andero AB, Rosenfeld A and Natour J: Effect of facet joint injection versus systemic steroids in low back pain: A randomized controlled trial. Spine (Phila Pa 1976) 38: 1995-2002, 2013.

33. Do KH, Ahn SH, Cho YW and Chang MC: Comparison of intra-articular lumbar facet joint pulsed radiofrequency and intra-articular lumbar facet joint corticosteroid injection for management of lumbar facet joint pain: A randomized controlled trial. Medicine (Baltimore) 96: e6524, 2017. 